\title{
CAT-TI: \\ E-learning, Goal-Setting, and Cataloging
}

\author{
Jacqueline Snider, University of lowa
}

\begin{abstract}
This article describes the techniques of applying a goal-setting program to an online tutorial on cataloging the title field. Training staff to catalog presents many challenges to librarians in management positions. The task, while necessary, is sometimes considered tedious. In addition, researchers report an extremely high learner dropout rate for online tutorials. Goal-setting programs enhance work performance, and facilitate the completion of online tutorials.
\end{abstract}

For some librarians, training staff to catalog presents a major challenge to their managerial and instructional skills as there are issues of time, cost, motivation, and persistence. To address the first two concerns of time and cost, e-learning or online instruction provides an effective domain in which to learn. An online tutorial allows staff to learn on the job, reduces travel and classroom training costs, and provides "just-in-time" training when information is needed the most. For motivation and persistence issues caused by the e-learning environment and the tutorial's subject matter, a goal-setting program offers structure to the training process. This article describes the benefits and drawbacks to online learning, and the techniques of applying a goal-setting program to an online tutorial on cataloging.

\section{E-learning: Pros and Cons}

A recent survey of corporate training reveals that e-learning in the form of self-study more than doubled from 7 percent in 2005 to 15 percent in 2006 ("2006 Industry Report," 2006). Librarians too are beginning to use online instruction for staff development purposes. According to a survey of 651 public, academic, special, and state libraries conducted by WebJunction in 2005, 70 percent intend to implement online learning in the next three years, while 49 percent will start within the next 12 months (Mason, Chesemore, \& Noord, 2006; "Trends in E-learning," 2006).

In their meta-analysis of fifteen major reports, Waight, Willing, And Wentling list the major features of online instruction as time, cost, location independence, "just-in-time" access to information, and learnercentered control (2002). Depending on the article, researchers describe these features in either positive (Rossett, 2002; DeLuca, 2002), or negative terms (CIPD, 2006; Clark \& Mayer, 2003).

\section{Time}

If employees do not need to leave their offices, and in some cases, travel long distances, to attend instructor-led training, then online instruction should save workers and employers a great deal of time. The flip side of this argument, however, is that employees feel that they do not have sufficient time to train ("Savvy Employers," 2001). By staying at their computers, they experience distractions. Ideally, employees should take online courses in an area away from their offices. They need adequate time to thoroughly work through the courses, and familiarize themselves with the technological requirements (DeRouin, Fritzsche, \& Salas, 2004). In two studies, Brown (2001; 2005) concluded that participants needed sufficient time to practice what they learned in their online courses as learning occurs through practice. However, he found that those who had the heaviest workloads were least likely to spend time training and practicing even though additional instruction would improve efficiency, and ultimately reduce their workload (Brown, 2005).

\section{Cost}

According to ASTD, employers spend on average $\$ 1,424$ per employee each year for training (Ketter, 2006). Other figures include an annual total of $\$ 50$ billion (Hudson, Bhandari, Peter, \& Bills, 2005), or $\$ 55.8$ billion ("2006 Industry Report," 2006). E-learning appeals to employers because it reaches more employees at the workplace, and reduces the amount spent on travel. While this may be true in theory, there are hidden costs. First, employers must install computer systems to deliver training online. This 
might be in the form of acquiring servers, establishing networks for internet training, contracting with elearning vendors for courseware, and upgrading office computers to support modules (DeLuca, 2002). Selecting courseware presents additional considerations. In some cases, employees require training in skills that are specific to a corporation or institution. E-learning vendors may not have the relevant courseware in their catalogs. Vendors who create training for specific purposes charge over $\$ 100$ an hour, and can ask almost $\$ 40,000$ for one hour of web-based training (DeRouin, Fritzsche, Salas, 2005). Employers are aware that e-learning is not inexpensive. In fact, $48.8 \%$ of the 133 employers, who responded to Learning Circuits 2005 survey, indicated that "cost to implement" was a major concern of elearning (ASTD, 2005). From the same survey, employers stated that they allocated less than ten percent of their training budget to technology-based instruction.

Librarians have many course providers available to them including WebJunction, SLA's newly launched Click University, Solinet, BCR, Amigos, and others ("Trends in E-Learning," 2006; Smithee, 2005). However, like corporations, a barrier to implementing e-learning is lack of funding ("Trends in E-Learning," 2006).

\section{Location Independence}

Staff in rural libraries and small, one-person special libraries are isolated, and restricted in attending offsite courses. Through online instruction, employees can access courses anytime, and anywhere (DeLuca, 2002). While theoretically this sounds appealing, the drawbacks associated with time also apply to location. Employees tend not to utilize online courses as they are over committed, susceptible to distractions, and short on other staff to fill in during their absence. By leaving the office or hanging a donot-disturb "I'm in training" sign on the door, an employee can concentrate on the lesson at hand.

\section{"Just-in-time" Learning}

Ten years ago, a manager at the Boeing Company (Kiser, 1999) created a CD-ROM program by using a camcorder to film a mechanical process that he wanted workers to adopt. This "quick and dirty" instruction video is a perfect example of "just-in-time" training. Because e-learning can be delivered to the desktop, it offers employees access to information that they need immediately in order to develop skills for a specific application. "Just-in-time" learning depends upon the anticipating employees' needs, and locating or developing the appropriate courseware (Alessi \& Trollip, 2001).

In WebJunction's survey, 55 percent gave "just-in-time" training as a reason for developing their own online instruction ("Trends in E-Learning," 2006). Off-the-shelf courseware offers an alternative to designing online programs particularly when staff do not have course development expertise, or time. Staff development topics specific to the library world are broad-based and relevant to many. There topics include cataloging, reference, information literacy, and marketing.

\section{Learner-Centered Training}

A key ingredient of technology-delivered training involves the learner controlling instruction. In other words, the employee decides when to access the online courseware, and guides the lesson (Horton, 2001; DeRouin, Fritzsche, \& Salas, 2004). Placing the learner in command often produces mixed results. What Brown discovered in his study of 78 employees of a Fortune 500 company is that motivation and goal orientation determined the participants' choices (2001). Some participants elected to terminate their training, and limit their practice time which resulted in poorer posttest scores. He concludes that "simply providing access to computers with training activities does not mean that trainees will use them to learn."

Computer-delivered instruction is more than just posting classroom courses onto the Web or CD ROM (Horton, 2001). The very nature of the electronic environment presents challenges. E-learning is learnerdriven, and therefore, solitary. The experience could be described as the loneliness of the long distance e-learner. Many students require social interaction and collaboration to learn (DeLuca, 2002). Computerbased courses can incorporate interactivity into the design to create a community of learners. This can be accomplished synchronously or asynchronously through discussion boards, email, or real-time chats (Clark \& Mayer, 2003). 
Several recent studies report dropout rates of 69 and 70 percent (Shepherd, 2003; Laine, 2003; Rossett \& Schafer, 2003; Van Liew, 2005; Weinstein, 2006). A study of 61 participants conducted by Learning Tree, an IT training firm showed that distractions and work commitments cut short training, and that the length of training determined the number of dropouts (Laine, 2003). Several of the study's participants attended instructor-led training as well. They found the classroom experience more satisfactory in terms of engagement, and preferred face-to-face interactions with the instructor and other students. Ironically, the classroom experience took more time than online instruction.

In a study of 204 employees, 67 percent dropped out of training due to time restrictions, interruptions, inability to concentrate, preferences for shorter periods of instruction, the difficulty of the content, or technology problems (Baldwin-Evans, 2004). The author concluded that participants dropped out because they received the exact amount of learning they required. They preferred "dipping in and out" of courses, and learned in chunks.

\section{Goal-Setting and Learning}

In short, well-developed and implemented online tutorials have positive potential for effective staff training. However, institutional factors also need to be carefully considered and integrated to insure effectiveness. Particularly if the task to learn is considered tedious, additional incentives need to be in place to motivate the learner. One such approach is a goal-setting program.

The elements of a goal-setting program include its application in the workplace, its use with repetitive, and boring tasks, and its focus on task performance. The most difficult goals produce the strongest performance, and difficult goals elicit better performance than when people are told "to do their best" (Locke and Latham, 2002). Feedback provides the necessary component to inform workers of the effectiveness of their performance. Learning how to catalog bibliographic records using an online tutorial contains all the features necessary for a goal-setting program. The topic, while essential, may not appeal to staff. And as noted previously, the e-learning environment presents obstacles to motivation and persistence.

\section{CAT-TI Tutorial}

A few years ago, I created a web-based tutorial, CAT-TI: A Tutorial for CATaloging the TItle field of MARC Bibliographic Records. I focused on the title field because patrons often search by title, and the topic is complex yet focused enough for one lesson of instruction. The tutorial incorporates the instructional design model, ADDIE, and takes into account issues that occur in designing courseware in an online environment.

Gustafson and Branch (2007) define the components of ADDIE as: Analysis, which involves a needs assessment to identify problems, learners, and formulate goals; Design, which outlines measurable objectives, learning activities, storyboards, flowcharts, and media; Development, which creates materials such as streaming video to support the elements described in the Design stage; Implementation, which delivers the instruction; and Evaluation, which includes either or both formative and summative. Formative evaluation provides feedback in order for the designer to improve, and revise instruction. Summative evaluation reflects the instruction's overall effectiveness and worth (Gustafson \& Branch, 2007). The major feature of ADDIE and other instructional models is congruence. Every aspect including goals, objectives, strategies, and evaluation must correspond in order to ensure effective instruction (Gustafson \& Branch, 2007; Smith \& Ragan, 2005).

The following detailed analysis and modification of the CAT-TI tutorial provides a case study in the process of integrating online factors and goal-setting program elements into the instructional design in order to develop more effective and efficient instruction.

\section{Goal-Setting Program}

The following eight steps constitute a goal-setting program. The process is outlined, noting the context of guiding library staff to complete the online tutorial. 
1. Identify the objective to be accomplished.

The start of a goal-setting program requires a clear statement of the objective that is to be accomplished. As shown in Figure 1, the objectives of CAT-TI are prominently included in the tutorial's introduction, and state that the learner will be able to: (1) select the first and second indicators for titles of items, and (2) determine the subfields to use for titles of items. According to Locke and Latham (2002), "[a] goal is the object or aim of an action, for example, to attain a specific standard of proficiency, usually within a specified time limit." The learner who starts CAT-TI understands that the goals of the program are to learn which indicators and subfields to use when defining the title entry in a MARC record. More importantly, I situate the objectives by describing a larger context for the title field. The title field is made up of data which ultimate forms the background of the online catalog. This allows patrons to search for material in the library.

Figure 1

Introduction to CAT-TI

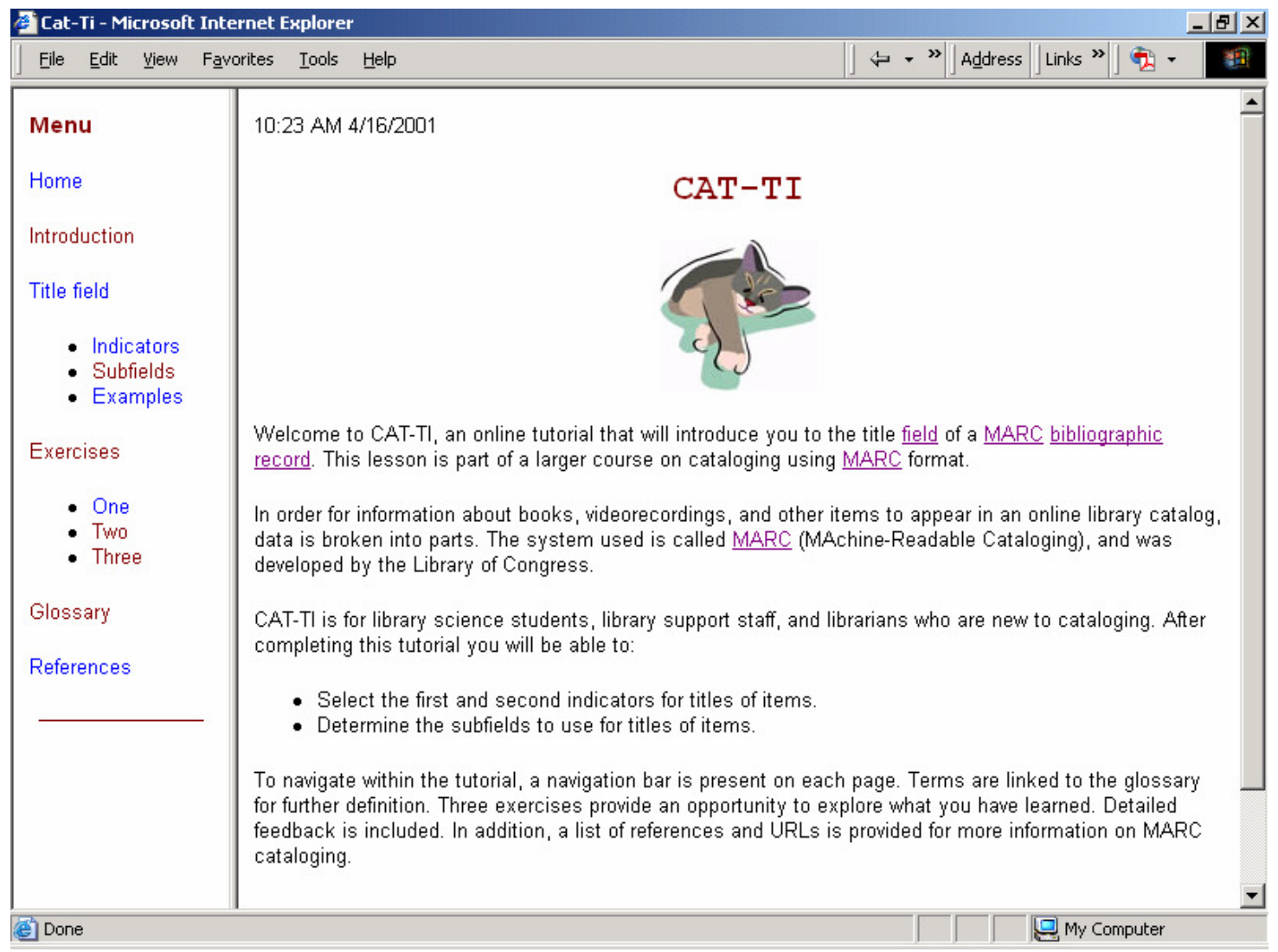

\section{Define goal difficulty.}

From their research and that of others, Locke and Latham (2002) illustrate that "moderately difficult goals" produce the best performance, while very difficult and very easy ones result in less optimum work. While I am not certain of the difficulty level that CAT-TI would fall into, I would contend that precision is important, and that level of accuracy might be considered somewhat difficult to attain. Library staff who catalog need to know how to apply the correct tags and subfields to the title field; otherwise, patrons will not be able to find titles in an online catalog. In the original tutorial, I did not specifically define goal difficulty. In a revised version of CAT-TI, I would clearly define goal difficulty by adding:

The concepts described in this tutorial are of moderate difficulty. Successful completion of the exercises in this tutorial represents an understanding of the importance, and mechanics of correctly cataloging the title field. 


\section{Define goal specificity.}

Goal specificity reduces ambiguity. The learner focuses on the task at hand, knows what to do, and what to expect (Reeve, 2005). In CAT-TI, the goals are very specific. Learners select the indicators and subfields of the title field. Why are the indicators so important? The second indicator controls the alphabetical indexing of the first word in the title field. If the definite article such as "the," and indefinite articles such as "a" or "an" are not taken into account, the database indexes the title alphabetically by "a," "an," or "the." When a patron searches for a title, and does not include the article, they may not retrieve the correct title because it is indexed by the article, and not the second word of the title. "The Sound and the Fury" is the example provided in the tutorial.

Indicator 2: Nonfiling characters

0-9 -- Number of nonfiling characters This indicator is set at zero, except when the title begins with an article. For example, in The sound and the fury, the second indicator would be set to 4 . The letters, $\mathbf{T}, \mathbf{h}, \mathbf{e}$, and the space following them are ignored in alphabetizing titles. The record will be automatically filed under "s" for sound.

\section{Specify in advance when performance will be measured/assessed.}

By stating in advance when performance will be measured, the learner is given feedback on her performance, and can keep track of her goal. Feedback is essential to performance. If the learner performs at a high level then she feels satisfaction, and discrepancy creation occurs with the possibility that the learner will create a more difficult goal. If the performance is at a low level, then the learner feels dissatisfied, and will try harder (Reeve, 2005). On the second screen of the original CAT-TI, I stated that the tutorial includes exercises at the end for learners to evaluate their conceptual understanding. Upon reflection, I provided exercises that were too few and too easy. In a revision of this tutorial, I would include a variety of exercises and feedback that build upon the learner's knowledge. I would disperse throughout the tutorial, not just at the end.

\section{Check on goal acceptance.}

Goal acceptance is an essential part of the goal-setting program as it involves the person's willingness to accept or refuse the goal (Reeve, 2005). In the workplace, goals are often imposed on workers. Staff need to accept the goal in order to increase performance or complete the assignment. If they do not accept the imposed goal, then the objectives of an organization or unit are unfulfilled. Thus, goals need to be internalized to improve performance (Reeve, 2005). Four factors determine goal acceptance: goal difficulty, employee participation in setting the goal, the credibility of the person setting the goal, and extrinsic rewards. In CAT-TI, the only way to determine goal acceptance is by discussing the tutorial with the staff member. Goal acceptance occurs between the facilitator and the learner. The facilitator will need to outline why the lesson is important, and what will be accomplished after completion. What spurs the staff member into working through the tutorial? While extrinsic motivation in the form of rewards is not totally in favor with motivation experts, it provides a powerful incentive in the workplace. In this instance, extrinsic motivation is present in terms of accomplishment. Once staff understand title field, they can move onto other parts of the record. The ultimate goal is to gain expertise in MARC, which presents an intellectual challenge and offers more responsibility.

\section{Discuss plans and strategies underlying goal attainment.}

Discussing plans and strategies is important in the goal-setting process because it makes the learner conscious of the actions that need to occur to succeed in reaching the goal (Locke \& Latham, 2002). CAT-TI does not provide a means to develop a plan or strategy for its successful completion; the learner just moves from screen to screen. Feedback from working through the exercises could provide a means to strategize and plan, but only to a limited extent, and only if the answer is incorrect. In a revision, I would add a worksheet that allows the learner to track the concepts that she worked through, the ones that were successfully completed, and the areas that need review.

\section{Create implementation intentions.}

Implementation intentions guide the learner in developing a plan to attain goals. In the workplace, implementation intentions are often tied to performance evaluations. Managers will indicate that the employee needs to develop skills or perform at a certain level in a specific area. Often the manager, in consultation with the employee, will create a schedule and a plan of action to accomplish these goals. In 
some cases, the successful completion of a course can satisfy the plan outlined by the manager and the employee. Since scheduling can be a problem, staff development courses and tutorials are scheduled during slower periods when there is sufficient time. Sometimes staff fit courses into their schedules. It is important for employees to take online courses away from their cubicles, and into work areas that are lowtraffic, to reduce distractions. This can all be discussed prior to taking the course. With CAT-TI, implementation intentions need to be discussed in advance with the learner. A specific time and plan should be decided upon for the employee to take the tutorial. There should also be a backup plan to help the learner follow through on the intention to take the tutorial. By specifying a certain day, time, and place to take the tutorial, the learner has the impetus to get started and ultimately finish (Reeve, 2005).

\section{Provide performance feedback.}

Feedback is essential in the goal-setting process as it guides the learner in terms of achieving the goal. Learners track their progress through feedback. The feedback communicates the level of performance the learner successfully reached. Feedback is incorporated into CAT-TI through exercises that assess the learner's understanding and competency. The multiple choice format inherently provides feedback. In figures 2 and 3, the learner selects the incorrect answer, and receives a message explaining why the answer is wrong. The input I created to let learners know if they answered successfully or unsuccessfully is intended to reinforce the lessons in the tutorial, and to return them to the information for additional review. Feedback is extremely important in making sure that cataloging is done correctly. It is very precise, because wrong indicators and tags can result in patrons not finding the items they need in the online catalog.

Figure 2

\section{CAT-TI Exercise 1}

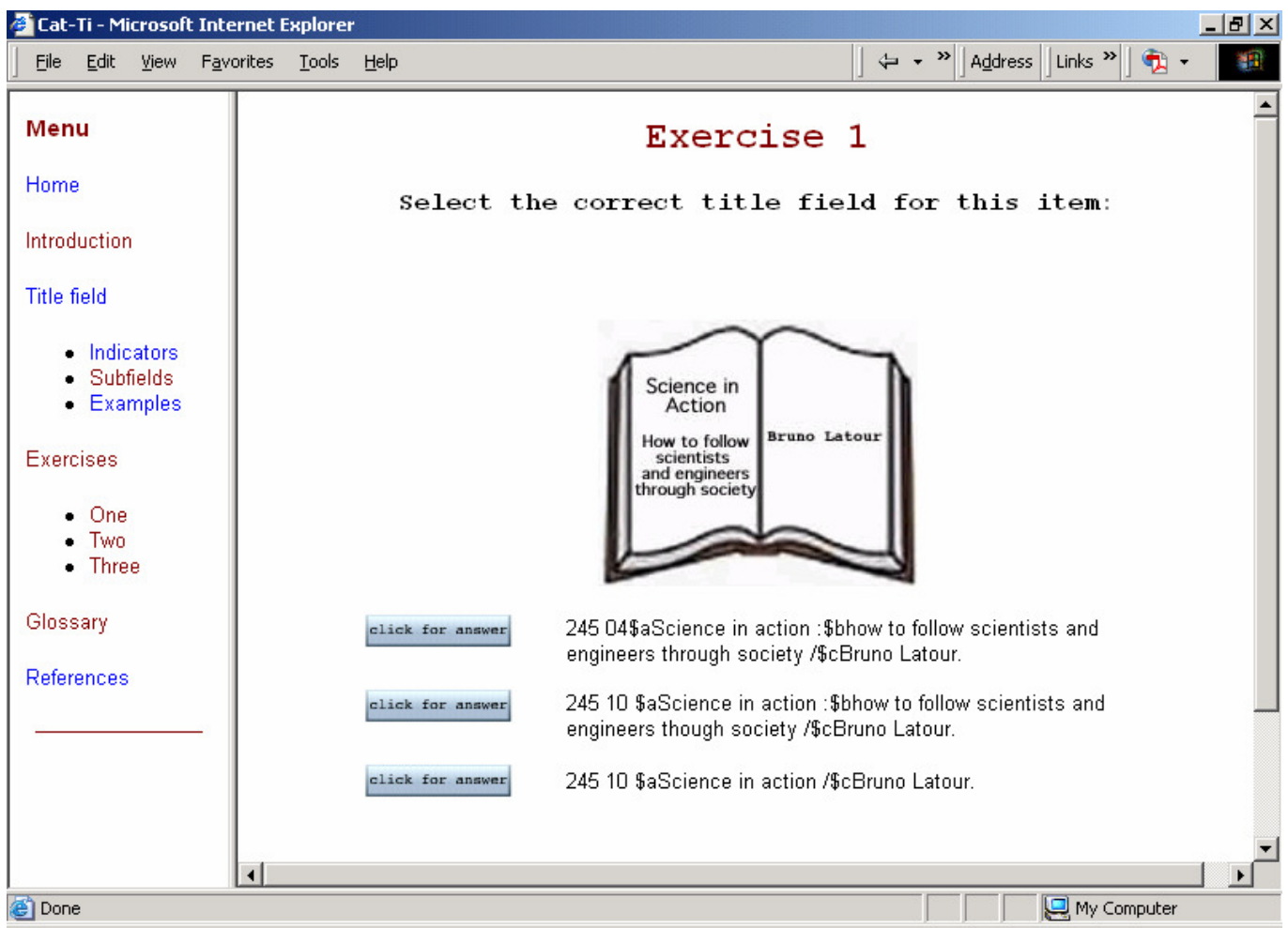


Figure 3

CAT-TI: Feedback for Exercise 1

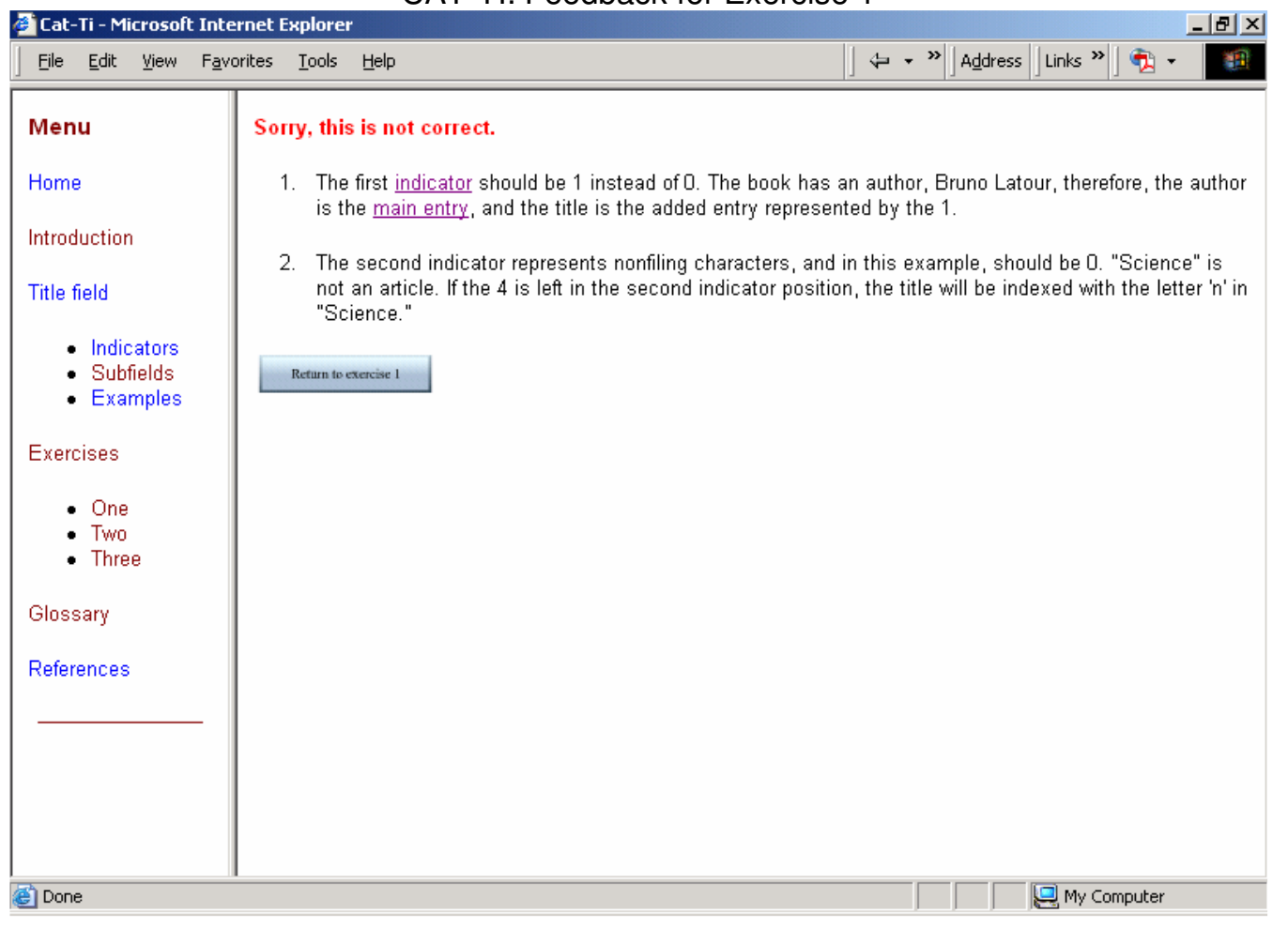

\section{Conclusions}

A goal-setting program provides the perfect structure for CAT-TI. According to Reeve, goal-setting was developed for the workplace to enhance employee performance (2005). Since cataloging exists in the library work environment for the essential purpose of organizing and accessing materials, a goal-setting program works well for this task. Goal-setting is best suited for boring and uninteresting tasks. For many, cataloging has limited creativity, and is very structured. Training staff to perform cataloging functions often presents a major challenge. A tutorial that incorporates goal-setting theory provides a structure within itself to help staff learn to perform this task. With regard to intrinsic motivation, one hopes that understanding what each concept means in a title field, and how to successfully apply this learning, will be in itself fulfilling. Once learners know how to catalog the title field, they move to other parts of the catalog record, which are often more interesting. In addition, the environment of an online tutorial can dissuade the learner from completing the lesson, and practicing the concepts presented. WebJunction addresses this on their website by including a list of suggestions to facilitate learning online ("E-learning Tips," n.d.).

In revising CAT-TI for it to fully incorporate all the elements of a goal-setting program, the following features should be added: defining goal difficulty; specifying early in the program when performance will be measured and providing sufficient feedback to indicate goal level; incorporating a means to check on goal acceptance; discussing plans and strategies to attain the goal; and creating implementation intentions. These elements, including the ones already in CAT-TI, can produce strong incentives for learners to complete the tutorial. Cataloging instruction challenges librarians. An online tutorial that incorporates goal-setting motivational and performance incentives to teach and transfer knowledge on this topic is essential. 


\section{References}

Alessi, S., \& Trollip, S. (2001). Multimedia for learning: Methods and development. $3^{\text {rd }}$ edition. Boston, Allyn and Bacon.

American Society for Training \& Development. (2005). E-learning trends 2005. Learning Circuits. Retrieved January 8, 2007 from http://www.learningcircuits.org/2005/dec2005/annualtrends.htm

Baldwin-Evans, K. (2004). Employees and e-learning: What do the end-users think? Industrial and Commercial Training, 36, 269-274.

Brown, K. (2005). A field study of employee e-learning activity and outcomes [Electronic version]. Human Resource Development Quarterly, 16, 465-80.

Brown, K. (2001). Using computers to deliver training: Which employees learn and Why? Personnel Psychology, 54, 271-296.

Chartered Institute of Personnel and Development. (2006). E-learning: Progress and prospects. Retrieved January 8, 2007 from http://www.cipd.co.uk

Clark, R., \& Mayer, R. (2003). E-Learning and the science of instruction: Proven guidelines for consumers and designers of multimedia learning. San Francisco, CA: Pfeiffer.

DeLuca, R. (2002). Using the internet to achieve your workplace training objectives [Electronic version]. Applied Occupational and Environmental Hygiene, 17, 814-817.

Derouin, R., Fritzsche, B., \& Salas, E. (2005). E-learning in organizations [Electronic version]. Journal of Management, 31, 920-940.

Derouin, R., Fritzsche, B., \& Salas, E. (2004). Optimizing e-learning: Research-based guidelines for learner-controlled training [Electronic version]. Human Resource Management, 43, 147-162.

E-learning tips and resources. (n.d.). Retrieved January 9, 2007, from http://webjunction.org/do/ Navigation?category $=13591$.

Gustafson, K., \& Branch, R. (2007). What is instructional design? In R. Reiser \& J. Dempsey (Eds.), Trends and issues in instructional design and technology ( $2^{\text {nd }}$ ed.). (pp. 10-16). Upper Saddle River, NJ: Pearson, Merrill, Prentice Hall.

Horton, W. (2001). Leading E-Learning. ASTD. Retrieved January 9, 2007, from http://library. books24x7.com/ proxy.lib.uiowa.edu.

Hudson, L., Bhandari, R., Peter, K., \& Bills, D.B. (2005). Labor force participation in formal work-related education in 2000-01. Washington, DC: National Center for Education Statistics.

Ketter, P. (2006). Investing in learning; looking for performance. $T+D, 60(12), 30-33$.

Kiser, K. (1999, June). Blue-collar training on the Web. Training, 36, 22-24.

Laine, L. (2003, June). Is e-learning e-ffective for IT training? $T+D, 57,55-60$.

Locke, E. A., \& Latham, G. P. (2002). Building a practically useful theory of goal setting and task motivation. American Psychologist, 57, 705-717.

Mason, M., Chesemore, S., \& Noord, R. (2006, Nov. 15). E-learning's next wave. Library Journal, 131(19), 40-43.

Reeve, J. (2005). Understanding motivation and emotion ( $4^{\text {th }}$ ed.). New York: Wiley.

Rossett, A. (2002). Waking in the night and thinking about e-learning. In A. Rossett (Ed.), The ASTD elearning handbook (pp. 3-18). New York: McGraw-Hill.

Rossett, A., \& Schafer, L. (2003). What to do about e-dropouts. $T+D, 57(6), 40-47$.

Shepherd, C. (2003). Complete the course. ITTraining, 42-45.

Savvy employers make e-learning part of their overall training strategy (2001). IOMA's Human Resource Department Management Report, 1, 6-8.

Smith, P., \& Ragan, T. (2005). Instructional design ( $3^{\text {rd }}$ ed.). New York: Wiley.

Smithee, J. (2005). FLA e-learning: Continuous learning for Florida librarians. Florida Libraries, 48, 6-8.

Trends in e-learning for library staff: A summary of research findings. (2006). Retrieved January 9, 2007, from http://webjunction.org/learningcenter.

2006 industry report. (2006, Dec.). Training, 43(12), 20-32.

Van Liew, R. (2005). Effective corporate IT training: Bursting the e-learning bubble. ITworld.com. Retrieved January 8, 2007, from http://www.itworld.com?Career/3710/050603elearning/

Van Liew, R. (2005). Live and in person: Why there is no substitute for classroom training. ComputerUser.com. Retrieved January 8, 2007, from http://www.computeruser.com/articles/ 2407.5,.88.1.0701.05.html 
Waight, C., Willging, P., \& Wentling, T. (2002). Recurrent themes in e-learning: A meta-analysis of major e-learning reports. Retrieved March 27, 2006, from http:/learning.ncsa.uiuc.edu/ papers/ AHRD2002 waight-willging-wentling.pdf

Weinstein, M. (2006). E-learning's dirty little secret. Training, 43(2), 6.

Jacqueline Snider is an adjunct faculty member of the University of lowa School of Library and Information Science. Email: jacqueline-snider@uiowa.edu

The next issue will focus on diversity issues, particulary in terms of outreach.

Some of the issues include:

- identifying under-served populations

- identifying ways to reach under-served populations

- assessing needs of diverse populations

- developing collections and services for diverse populations

- developing outreach strategies to reach diverse populations

These are just a few of the possibilities for topics to write about. The deadline is April 15. Additional book reviewers are also welcome. Email queries and manuscripts to Editor Dr. Lesley Farmer at Ifarmer@csulb.edu

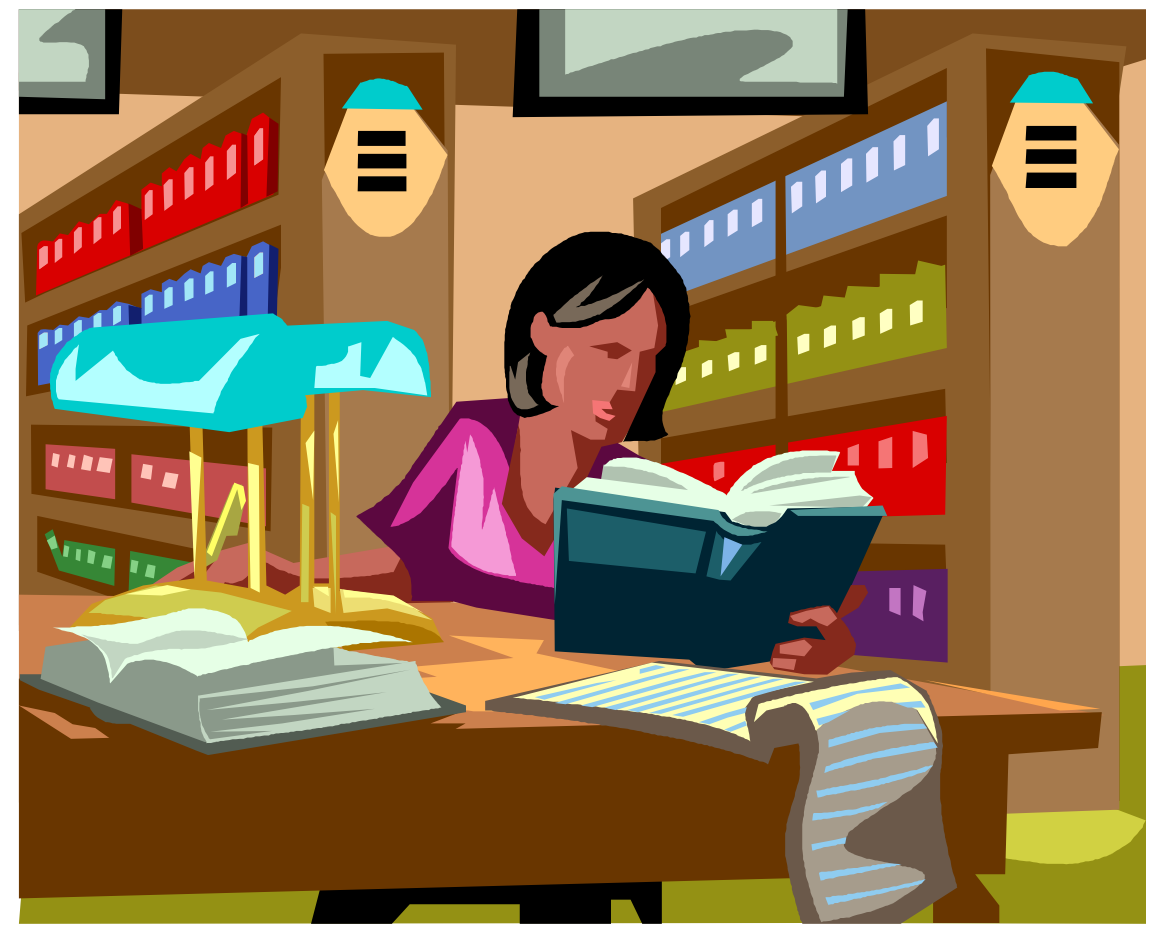

